\title{
The role of pulmonary surfactant in obstructive airways disease
}

\author{
J. Hohlfeld*, H. Fabel*, H. Hamm**
}

The role of pulmonary surfactant in obstructive airways disease. J. Hohlfeld, H. Fabel, H. Hamm. (CERS Journals Ltd. 1997.

ABSTRACT: Pulmonary surfactant research has an increasing impact on treatment considerations in adult respiratory disorders, above all acute respiratory distress syndrome (ARDS). Obstructive airways diseases have only been sporadically addressed in this respect. In the last decade, direct and circumstantial evidence for surfactant as a contributing factor in the regulation of airway calibre has emerged.

Morphologically, a bronchiolar surfactant layer has been demonstrated, whereby the airways are mostly supplied by alveolar surfactant components via the mucociliary escalator. Functionally, prevention of airway film collapse and collapse of the airway walls are important surfactant properties in maintaining airway stability. In addition to its surface activity, airway surfactant improves bronchial clearance and regulates airway liquid balance, thus indirectly modulating airway wall thickness and airway diameter. Surfactant has furthermore been shown to modulate the function of respiratory inflammatory cells. Its immunomodulatory activity includes suppression of cytokine secretion and transcription factor activation. This may be of importance in the inflammatory network of asthma.

Thus, dysfunction of surfactant in obstructive lung disease might be one of the mechanisms leading to increased airway resistance, which is commonly thought to be due to narrowing of airways under humoral and nervous control. In animal models of asthma, surfactant dysfunction was demonstrated, which was possibly due to protein inhibition. Furthermore, surfactant therapy seems to be capable of preventing allergen-induced bronchoconstriction. Human studies on surfactant impairment in obstructive airways diseases are still scarce but the data available are consistent with animal studies.

Antiobstructive pharmacotherapy, mainly with corticosteroids, might influence and improve airway surfactant balance, but the exact mechanisms and the overall effect of pharmacotherapy on surfactant function in obstructive airways disease has to be further elucidated. Our knowledge about the role of pulmonary surfactant in obstructive airways disease is still limited, but there is convincing evidence that pulmonary surfactant plays a role in keeping the airways open.

Eur Respir J 1997; 10: 482-491.

*Dept of Respiratory Medicine, Hannover Medical School, Hannover, Germany. **Dept of Respiratory Medicine, AlbertLudwigs-University, Freiburg, Germany.

Correspondence: J. Hohlfeld Dept of Respiratory Medicine Hannover Medical School Konstanty-Gutschow-Str. 8 D-30625 Hannover Germany

Keywords: Airway obstruction airway resistance

asthma

chronic obstructive pulmonary disease pulmonary surfactant surfactant dysfunction

Received: June 241996

Accepted after revision November 51996
Sixty seven years of pulmonary surfactant research have passed and our knowledge about surfactant in research and clinical practice is still increasing exponentially. Today, the precise composition of alveolar surfactant is known, the alveolar type II cell has been identified as the site of alveolar surfactant synthesis, and details concerning surfactant synthesis and secretion and its regulation and metabolism have been elucidated. It was in 1929, that vON NEERGARD [1] first postulated the existence of a surface active material in the lungs. Its pathogenetic role was initially described in hyaline membrane disease of preterm infants as a quantitative surfactant deficiency by AvERY and MEAD [2]. Today, replacement therapy with exogenous surfactant is an established therapy in infant respiratory distress syndrome (IRDS).

For a long time, putative surfactant dysfunctions have been ignored by clinicians in adult respiratory medicine but there is increasing evidence of its relevance in adult respiratory disorders [3]. Biochemical and biophysical surfactant abnormalities have been reported in various diseases, such as the acute respiratory distress syndrome (ARDS), pneumonia, cardiogenic lung oedema [4], asthma [5], after cardiopulmonary bypass surgery [6, 7], in mechanically-ventilated patients [8], and following lung transplantation [9]. Clinical pilot studies with exogenous surfactant in these diseases have shown potential benefits [10-12], but the number of patients is low and experience is limited due to the still enormous costs of surfactant therapy in adults.

Obstructive lung disease is a major health problem, as it causes substantial morbidity and, at present, has an increasing prevalence of approximately $10 \%$ in industrialized countries. Obstructive lung diseases include a number of acute and chronic pulmonary disorders associated 
with temporary or chronic reduction of expiratory flow. Asthma is characterized by a variable and reversible airway obstruction due to airway inflammation and bronchial hyperresponsiveness. Chronic obstructive pulmonary disease (COPD) is defined as a condition in which there is permanent obstruction to airflow due to chronic bronchitis and/or emphysema. Besides contraction of bronchial smooth muscles, airway oedema and mucosal secretions play a role.

Little is known about the role of pulmonary surfactant in obstructive airways disease. Whereas lung damage with dysfunction of alveolar surfactant is of importance in various respiratory diseases, such as ARDS or pneumonia, alveolar surfactant dysfunction does not seem to play a major role in obstructive airways disease. On the contrary, surfactant impairment in the airways as a secondary consequence of airway inflammation might have a major impact on small airway function. Thus, dysfunction of surfactant in the airways might be a contributory factor to airway obstruction and increased airway resistance in obstructive lung disease. In the last decade, direct and indirect evidence has emerged for surfactant as a factor in the regulation of airway calibres. Surfactant may be of greater importance in the airways than has been previously recognized. This review will discuss those aspects of airway mechanics that are closely related to the function of pulmonary surfactant. However, some of the mechanisms discussed may be of secondary rather than primary importance in obstructive airways disease.

\section{Surfactant physiology in the airways}

Pulmonary surfactant is a mixture of phospholipids (PL) and surfactant specific proteins [13]. Its components are synthesized in the alveolar region by type II pneumocytes. Surfactant proteins are also synthesized, albeit to a lesser extent, in Clara cells of the peripheral airways [14-17]. Research into surfactant physiology has mainly focused on the alveolar compartment. In this chapter, we will concentrate on "airway" surfactant physiology. For further information on "alveolar" surfactant physiology, the interested reader is referred to a number of articles which review these aspects [3, 1821].

\section{Origin and composition}

The airways are supplied with alveolar surfactant components via the mucociliary escalator, as the surfactant film at the alveolar air/liquid interface is partly extruded into adjacent conducting airways during expiration. Approximately $7 \%$ of alveolar surfactant reaches the bronchial tree by this mechanism [22]. Every state of alveolar surfactant deficiency might, therefore, involve the peripheral airways. A bronchiolar surfactant layer has been demonstrated by electron microscopy [23] between the sol and gel phase of airway mucus [24]. There are no data on differences of alveolar and bronchiolar surfactant composition in man. In porcine lungs, the biochemical composition of phospholipids and phosphatidylcholine molecular species as an indicator of alveolar origin appears to be similar, although the ability to lower surface tension is markedly decreased in bronchial surfactant [25]. SchÜRCH et al. [26] demonstrated that surface tension in the conducting airways of hamsters is approximately $30 \mathrm{mN} \cdot \mathrm{m}^{-1}$ using an elegant in situ microdroplet method previously described by the same group $[27,28]$. Similar surface tensions were confirmed for rat and guinea-pig tracheae [29]. Differences in the fatty acid profiles of tracheal and bronchoalveolar lavage (BAL) from sheep suggest local synthesis and release of phospholipids by tracheal epithelial cells [30]. Moreover, using a high-resolution cytochemical enzyme-gold technique, phospholipids have been identified in submucosal human airway secretory cells, suggesting that phospholipid is produced in airway cells and secreted into the airway lumen [31].

\section{Physiological functions}

Airway stability. Pulmonary surfactant is not only important for the stability of the alveoli, but also for small airway function. This was described as early as 1970 by MACKLEM et al. [32]. They found experimental and morphological evidence that, in terminal bronchioles of less than $0.5 \mathrm{~mm}$ in diameter, surfactant played a role in preventing bronchiolar collapse during deflation. Low surface tension minimizes the magnitude of negative pressure in the airway liquid layer possibly reducing the tendency for airway wall ("compliant") collapse (fig. 1) [33]. As illustrated by the law of Laplace for cylinders $(P=\gamma / \mathrm{r})$, where $P$ is transmural airway pressure, $\gamma$ is surface tension $\left(\approx 70 \mathrm{mN} \cdot \mathrm{m}^{-1}\right.$ for water $)$, and $\mathrm{r}$ is airway radius $(\approx 0.5 \mathrm{~mm}$ for terminal bronchioles), a surfactant-lacking bronchiolar lining layer with surface properties of water would result in a transmural pressure of 3-5 $\mathrm{cm} \mathrm{H}_{2} \mathrm{O}$, enough for these membranous, noncartilagineous airways to collapse. Furthermore, surfactant may prevent liquid-bridging in the airways by

a)

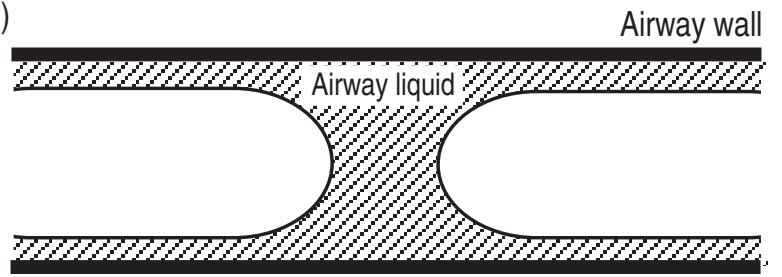

b)

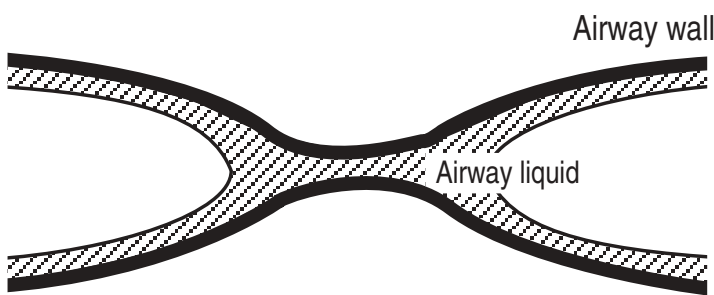

Fig. 1. - Schematic view of an airway showing: a) "film collapse" with liquid bridge formation due to impaired surfactant function, resulting in accumulation of airway liquid and fluid instability; and b) "compliant collapse" as a result of a decrease in effective transmural pressure, possibly due to a surfactant-dependent reduction of inner wall pressure. Both film collapse and compliant collapse will tend to occur simultaneously. However, local factors, such as liquid volume and airway wall properties, will determine the predominant type of collapse. 
reducing mean surface tension and surface tension gradients. It has been shown that instability of the liquid film in the airways due to impaired surfactant function can result in airway closure [34]. Thus, airway closure may occur by meniscus formation of the airway lining film (film collapse) and due to collapse of the bronchiolar wall (compliant collapse) (fig. 1).

Adhesive properties of the airway lining fluid, such as surface tension and viscosity, determine airway reopening [35]. Models of airway closure, including both film collapse and compliant collapse, demonstrate that there is a critical film thickness above which liquid bridges form. This was shown to be dependent on the properties of the fluid, the wall and the surfactant [36]. LIU et al. [37] found that small rigid tubes with small intraluminal fluid deposits containing surfactant remained patent after airflow ceased. In contrast, using only saline-containing fluid deposits the tubes refilled spontaneously. GAVER et al. [35] similarly showed that closing and narrowing of airways could depend on the surface tension at the lumen air-water interface in a flexible airway model. Furthermore, the ability of surfactant to maintain free airflow through a narrow tube was lost with the addition of albumin or fibrinogen (two potent surfactant inhibitors). Surfactant function was seriously affected by hydrolysis with phospholipase $\mathrm{C}$ but not with phospholipase $\mathrm{A}_{2}$ [38].

Airway liquid balance. A number of chemically distinct mediators cause influx of liquid into the airway wall and lumen, thus altering airway liquid balance. In addition, pulmonary surfactant possibly exerts an influence on airway fluid homeostasis. Loss of surface activity would result in additional inward forces that cause fluid influx into the airway lumen [39]. Thus, airway fluid balance is influenced and partly regulated by a functioning, surfactant containing bronchiolar lining layer. This also includes prevention of desiccation of the airways.

Bronchial clearance. Surfactant improves bronchial clearance by optimizing transport of particles and bacteria from the peripheral to the more central airways [26, 40, 41]. Moreover, exogenous surfactant has been shown to enhance mucociliary clearance [42]. Bronchioles lack a ciliated epithelium and, therefore, its function of directional clearance. This is compensated by periodic compression and decompression of the lining film in alveoli and peripheral airways during the breathing cycle, resulting in a net central transport [43]. In the more central, ciliated airways, surfactant-derived phospholipids are located between the gel and the sol phase of airway mucus [40]. Here, surfactant material is thought to regulate the proportion of the gel and the sol phase, to reduce mucus adhesiveness, to increase ciliary function [44], and therefore to optimize mucociliary clearance.

Immunomodulation. Surfactant has been shown to modulate the function of respiratory inflammatory cells [4547]. Surfactant proteins-A (SP-A) and -D (SP-D) enhance various alveolar macrophage functions, such as binding, opsonization and phagocytosis of infectious agents [48, 49]. Furthermore, SP-A may be important in host defence against bacteria and viruses [3]. For example, SP-A is able to neutralize influenza A viruses [50]. Moreover, SP-A binds to pollen grains, suggesting a role in protection against particles [51]. Surfactant phospholipids seem to be able to downregulate local lymphocyte activities [45, 52, 53]. Recently, SP-A has also been shown to inhibit lymphocyte proliferation and cytokine production in vitro [54].

Barrier function. HILLS [55] very recently outlined the concept of a partial barrier function of surfactant separating bronchial air from the receptors that elicit bronchoconstriction. Moreover, there is circumstantial evidence that surfactant is capable of inhibiting receptor-mediated bronchoconstriction. BERGMANN et al. [56] found that BAL fluid from guinea-pig lungs prevented angiotensinII receptor-mediated contraction of guinea-pig ileum in vitro. Experiments carried out by our own group have shown that aerosolized surfactant inhibits acetylcholineinduced bronchoconstriction in rats. Surfactant inhalation of only $40 \mu \mathrm{g} \cdot \mathrm{kg}^{-1}$ reduced the increase of lung resistance due to acetylcholine challenge to about $50 \%$, compared to untreated control animals [57]. We found that simultaneous pretreatment with an aerosolized combination of surfactant and the $\beta_{2}$-agonist terbutaline exhibited no further protective effect on acetylcholine-induced bronchoconstriction [58]. These data suggest that surfactant might protect the airways from exogenous stimuli, such as pharmacological and/or irritating agents. This view of a "surfactant barrier" in the airways is supported by the observation that intratracheal administration of adrenaline induces increased haemodynamic effects in surfactant-depleted rats, compared to nondepleted animals [59].

\section{Pathophysiology and role of surfactant in airway obstruction}

Obstruction of the airways is a multiform scenario. Airway narrowing is caused by smooth muscle constriction, mucosal oedema, secretion of (proteinaceous) fluid into the airway lumen, and airway inflammation. Mechanical factors, such as loss of lung recoil forces, have, furthermore, been shown to influence airway dimensions $[60,61]$. Smooth muscle constriction directly narrows airway diameter, whereas accumulation of liquid within the airway wall during an inflammatory process increases wall thickness, thereby inducing airway obstruction as luminal area decreases [62]. In addition, increased wall thickness potentiates the effect of smooth muscle constriction [63]. Accumulation of liquid in the airway lumen directly narrows airway dimensions.

\section{Airway stability and airway liquid balance}

Airway obstruction in asthma is now generally accepted to be due to chronic airway inflammation, with cellular infiltration of the airway mucosa. A number of inflammatory cells are enrolled, mainly eosinophils, mast cells and lymphocytes. Potent mediators are released that can induce smooth muscle contraction. Inflammatory stimuli induce extravasation of plasma from postcapillary venules into the airway wall and lumen by affecting endothelial and epithelial permeability. Tissue 
and luminal distribution of the plasma exudate may increasingly lead to local accumulation of plasma-derived proteins [64]. As plasma proteins are well-known inhibitors of surfactant function [65-67], this exudate can dramatically amplify the obstructive effect of smooth muscle contraction by interacting with bronchial surfactant and by directly filling the airway lumen. Protein-induced surfactant inhibition leads to decreased surface activity in the airways, with additional luminal inward force. Further fluid accumulation, with filling of airway interstices, amplifies airway constriction [63], probably leading to a vicious cycle of potentiation of bronchoconstriction in inflamed airways. A recent study by ENHORNING et al. [68] demonstrated that the ability to maintain free airflow in narrow conducting airways of rats is dependent on the quality of surfactant. These results could explain increased airway resistance, in part, as a blockade of conducting airways by liquid columns. Thus, airway surfactant dysfunction can cause airway narrowing and closure, whereas surfactant integrity achieves airway stability by inducing and maintaining low surface tensions.

\section{Airway inflammation and immunomodulation}

The role of pulmonary surfactant in the pathogenesis of airway inflammation and the impact on asthma has as yet only rarely been addressed [69]. Liu et al. [70] recently showed that surfactant dysfunction developed in sensitized guinea-pigs challenged with aerosolized ovalbumin. Surface activity of BAL from immunized, challenged animals was significantly reduced compared to control animals. The phospholipid concentration and composition, however, was unaffected, whereas protein content in BAL was significantly elevated compared to controls. The authors concluded that surfactant function in guinea-pigs with an acute asthmatic reaction was impaired due to inhibition by proteins leaking into the airways. This view is supported by a clinical study [71] that showed an increased bronchial clearance of $99 \mathrm{~m}$ technetium-diethylenetriamine penta-acetic acid (DTPA) in acute but not chronic asthma, indicating an increased permeability of the bronchial mucosa with subsequent protein leakage. Several years ago, LACHMANN and BECHER $[72,73]$ described the inhibition of allergic bronchoconstriction in guinea-pigs after intrabronchial surfactant instillation. They found that sensitized guinea-pigs pretreated by tracheal instillation of surfactant $(180 \mathrm{mg}$ phospholipids $\cdot \mathrm{kg}^{-1}$ body weight (BW)) showed a significantly lesser decrease in tidal volume after ovalbumin challenge compared to vehicle or untreated control. The authors concluded that surfactant might be protective against allergic bronchoconstriction. Recently, LiU and co-workers [74] also found that prophylactic intratracheal surfactant administration (17.5 mg calf lung surfactant extract) alleviates asthmatic reactions after antigen challenge in sensitized guinea-pigs.

Recently, VAN DE GRAAF et al. [5] found decreased SP-A levels in BAL fluid of asthmatics in comparison to healthy controls. Reduced SP-A levels in asthmatics could reflect an impaired resistance against pulmonary inflammation, with further disturbance of the surfactant system. In addition, decreased SP-A levels were found to increase the rate of surfactant subfraction aggregate conversion into poorly functioning small aggregates [75]. Thus, it could be speculated that the increased rate of small aggregates might be one possible explanation for surfactant dysfunction in asthmatics, under the assumption that large aggregate surfactant is substantially important for airway surfactant function. However, surfactant subfraction data on human BAL of asthmatics are not yet available.

Finally, it may be hypothesized that the immunomodulatory surfactant effects contribute to the downregulation of airway inflammation during acute asthmatic reactions. Cytokines, such as interleukin-1 $($ IL-1 $1 \beta$ ) and tumour necrosis factor- $\alpha$ (TNF- $\alpha)$ are involved in airway inflammation and are elevated in asthma [76]. Both IL- $1 \beta$ and TNF- $\alpha$ are potent inducers of the transcription factor, nuclear factor $-\kappa \mathrm{B}(\mathrm{NF}-\kappa \mathrm{B})[77]$. NF- $\kappa \mathrm{B}$ is now recognized as an almost ubiquitous transcriptional activator of immune and primary response genes [78]. It was recently found that surfactant suppresses NF- $\kappa B$ activation in human monocytic cells [79]. The inhibitory effect of surfactant on inflammatory cytokine production may, thus, involve transcriptional regulation through inhibition of NF- $\kappa \mathrm{B}$ activation. However, the precise role of surfactant in the immunoregulatory network of asthmatic airway inflammation has to be defined by further research.

\section{Mechanical factors}

An important concept derived from anatomical investigations is that alveolar walls do not act as perfectly elastic extensible structures. BACHOFEN and co-workers [80, 81] pointed out that lungs are deflated to low volumes where alveolar septa "crumple" into alveolar corners leaving the air/water surface and other tissue structures to contribute to recoil pressure. The structure of the alveolar duct is maintained by two networks of force-bearing elements. Firstly, the surface tension-insensitive peripheral connective tissue system starting from the pleura and extending into interlobular fissures; and, secondly, the terminal part of the axial fibre system that surrounds bronchi, being extended by the outward force of surface tension. It should be considered that increased surface tension in lung units can help to expand airways. Conversely, a decrease of recoil forces of surface and tissue origin could act to narrow airways, leading to increased resistance $[60,82]$. In emphysema, increased airway resistance is associated with a decrease of recoil forces, which is possibly also caused by a loss of surface recoil forces due to surfactant impairment, besides an impairment of tissue recoil forces.

\section{Regulatory aspects of surfactant synthesis and secretion}

The above-mentioned components of airway obstruction, such as smooth muscle constriction, fluid accumulation and oedema, occur with varying intensity and localization. Inhomogenous distribution of airway narrowing may lead to regional dystelectasis of some parts of the lung, whereas other lung sections are hyperinflated. Mechanical distension directly stimulates cultured type II cells to secrete surfactant [83]. In contrast, hyperinflation with mechanical overdistension may have 
adverse effects on pulmonary surfactant content [84]. Ventilation itself is an important stimulus for surfactant secretion [85]. In vivo, the calculated rate of basal secretion of surfactant phospholipids is about $10 \%$ of the stored intracellular pool per hour [86]. Basal secretion in vitro in the absence of exogenous agonists and physical stretch is about $1 \%$ per hour. Maximum stimulation by agonists in the absence of stretch forces can induce a secretory rate of about $8 \%$ per hour in vitro [87]. Hyperventilation, however, was shown to increase the secretory rate 14 fold [88]. Since the effects of agonists are modest, the majority of surfactant secretion seems to be stimulated by ventilation-induced physical forces. Thus, areas of hypoventilation may be driven into a vicious circle by a further decrease of their local surfactant content, finally resulting in airway closure. This in turn may potentiate the local inflammatory response as alveolar and bronchial clearance of infectious and irritant agents and mediators is seriously impaired.

\section{Smoking and obstructive airways disease}

Cigarette smoking is a major cause of COPD. There is evidence to suggest that smoking, in itself, can induce alterations of the surfactant system $[89,90]$. HuGHES and HASLAm [91] found increases in concentrations of phosphatidylglycerol, phosphatidylethanolamine and sphingomyelin, but lower levels of cholesterol and cholesterol: total phospholipid ratio in BAL fluids from 13 smokers compared to 9 nonsmoking controls. This was confirmed by a report of LUSUARDI et al. [92], who found an increased ratio of phosphatidylglycerol/cardiolipin and decrease of total phospholipids in BAL of 20 smoking, nonasthmatic COPD patients compared to 5 nonsmoking healthy controls [92]. This was interpreted as a smokeinduced stimulation of type II cells, with reactive hyperproduction of phosphatidylglycerol. SCHMEKEL et al. [93] similarly reported a decrease in total phospholipid and impaired surface activity in BAL of smokers. Their finding of similar albumin recovery in smokers and nonsmokers supports the hypothesis of surfactant dysfunction in smokers rather than abnormal permeability of the alveolar epithelium. In contrast, MANCINI et al. [94] found unchanged amounts of surfactant phospholipid in short-term smokers, but phosphatidylethanolamine was raised, and the ratio of phosphatidylcholine to sphingomyelin was significantly decreased. Studies on interactions of tobacco smoke with pulmonary surfactant by HigENBOTTAM [95] revealed that only whole smoke but not the gas phase caused a loss of surface activity. Thus, it was hypothesized that smoke particle constituents, such as fatty acids and sterols, interact with the phospholipid monolayer during compression.
Although cigarette smoke has been shown to disturb the integrity of the surfactant system, there are no data demonstrating that surfactant dysfunction plays a key role in the pathogenesis of COPD. However, a surfactant imbalance with airway collapse and air-trapping could promote emphysema due to alveolar hyperinflation and destruction.

Figure 2 proposes and summarizes the complex scenario of the possible role of surfactant in the pathogenesis of airway obstruction. Finally, one has to keep in mind that although surfactant may play a role of greater importance than has been recognized in the airways in the past, some of the possible mechanisms and proposals may be of secondary rather than primary importance in the pathophysiological role of surfactant in obstructive airways disease.

\section{Therapeutic aspects of surfactant}

\section{Exogenous surfactant therapy}

As mentioned above, exogenous surfactant treatment has been shown to influence allergic airway obstruction in animal models of asthma [72-74]. However, human data are rare. Only two clinical surfactant treatment studies exist, so far in asthmatics. In a double-blind, placebocontrolled pilot study of surfactant inhalation in patients during acute asthmatic attacks [10], aerosolization of 1 $\mathrm{mL}$ containing $10 \mathrm{mg}$ phospholipids led to an improvement of pulmonary function in surfactant-treated patients, with a significant increase in forced expiratory volume in one second (FEV1), forced vital capacity (FVC) and arterial oxygen tension $\left(\mathrm{P}_{\mathrm{a}}, \mathrm{O}_{2}\right)$ values of 27,12 and $13 \%$,

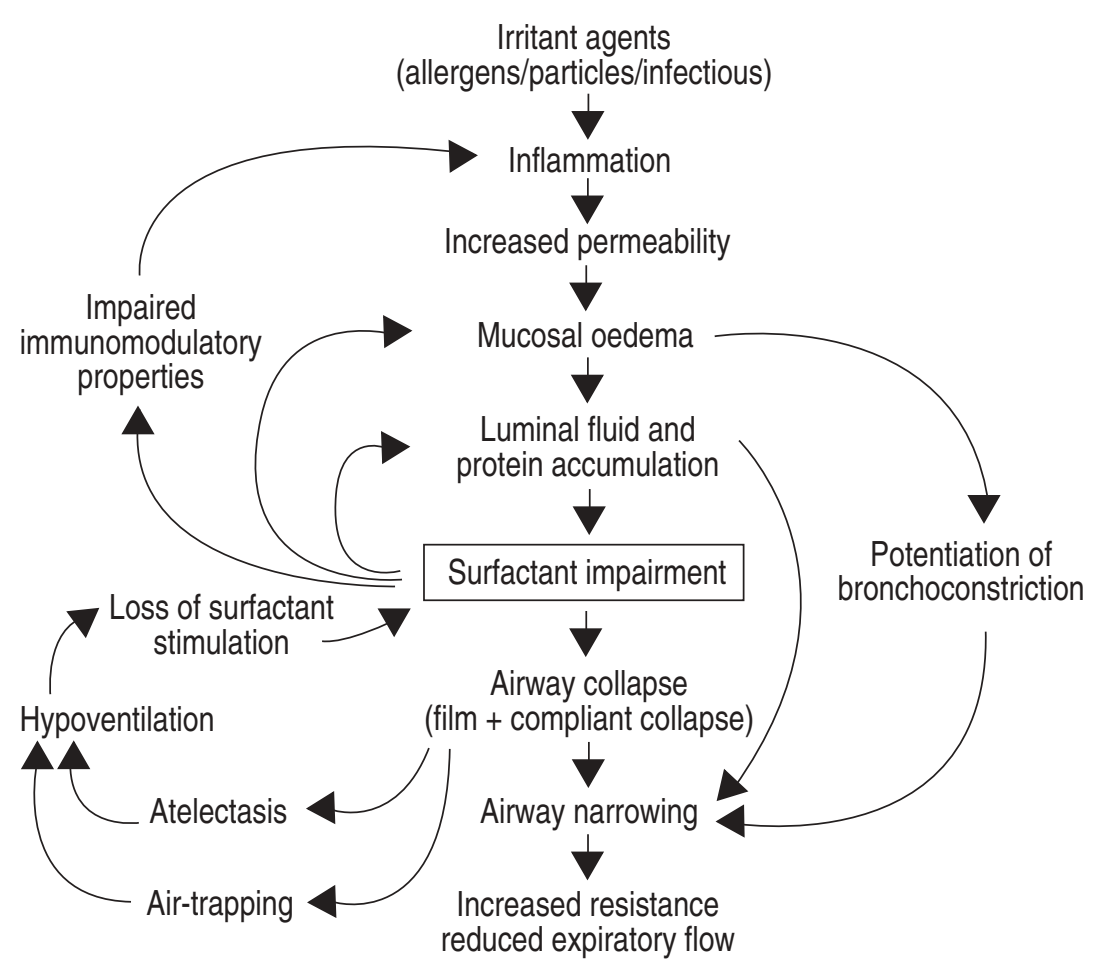

Fig. 2. - The possible role of pulmonary surfactant in the pathogenesis of airway obstruction. 
respectively. In comparison to exogenous surfactant supplementation studies in IRDS and ARDS, the effective surfactant dose was very low. In another study, nebulization of $100 \mathrm{mg}$ bovine surfactant (Alveofact ${ }^{\circledR}$ ) in asthmatic children with mild airflow limitation did not alter airflow obstruction and bronchial responsiveness to histamine [96]. The amount of surfactant deposited into the lungs was assessed to be as low as approximately $2 \mathrm{mg}$ per patient. WIRTZ et al. [97] presented a case where exogenous surfactant was successfully applied to a patient with severe exacerbation of COPD requiring mechanical ventilation [97]. A total of $800 \mathrm{mg}$ phospholipids (32 mL Survanta ${ }^{\mathrm{TM}}$ ) was instilled via a bronchoscope, leading to improvement of lung mechanics. Oxygenation index, compliance and minute volume increased and the patient could subsequently be weaned from the ventilator.

In conclusion, these results demonstrate that exogenous surfactant might have at least some beneficial effects when given to patients with acute airway obstruction. However, we are far away from answering the most important questions on dosage, timing, mode of application and, last but not least, necessity and justification of an expensive exogenous surfactant therapy in obstructive airways disease.

\section{Conventional antiobstructive therapy}

$\beta$-adrenergic agonists. Inhaled $\beta_{2}$-adrenoceptor agonists are first-line therapy in acute asthma attacks and episodes of acute airway obstruction [98]. They are the most effective symptomatic relievers of airway obstruction. Beta $_{2}$-agonists act directly on airway smooth muscles via the $\beta_{2}$-adrenoceptor, leading to bronchodilatation. Beta $_{2}$-agonists were found to stimulate surfactant secretion in the isolated perfused lung [99], and in isolated type II cells [100, 101]. Moreover, $\beta$-adrenergic agonists stimulate the uptake of extracellular surfactant in the isolated lung [102]. Premature infants whose mothers received tocolytic $\beta_{2}$-agonists shortly before birth were found to have a lower incidence of IRDS, indicating a potential stimulation of the developing surfactant system [103]. Thus, stimulation of surfactant secretion by $\beta_{2}$-agonists could contribute to the beneficial effect of these agents in the treatment of airway obstruction. However, the overall importance of $\beta_{2}$-agonists on airway surfactant balance has to be defined.

Corticosteroids. Treatment with inhaled steroids has been recognized as first-line therapy in asthma, when regular daily treatment is needed. The treatment of COPD has often been influenced by trends in asthma treatment, as many of the characteristics of COPD are similar to those of asthma. Thus, inhaled steroids are widely-used in COPD, but documentation of their effects are rare and the results from the studies available are contradictory. Corticosteroids increase synthesis and secretion of surfactant components [104]. They induce fatty acid synthase, as shown by an increase of fatty acid synthase messenger ribonucleic acid (mRNA) and enzyme protein [105]. Chronic steroid treatment of rats increases alveolar surfactant pools and SP-A levels [106, 107]. Surfactant may enhance the anti-inflammatory effect of corticosteroids by a recently described surfactant-induced suppression of the transcription factor NF- $\kappa \mathrm{B}$ activation [79], as NF- $\mathrm{KB}$ is known to regulate numerous proinflammatory genes. Taken together, corticosteroids may improve airway surfactant balance, possibly leading to a synergistic anti-inflammatory and antiobstructive effect.

Anticholinergic agents. Anticholinergic agents act as bronchodilators by blocking vagal bronchomotor activity [108]. These vagal bronchomotor influences are thought to be the most important nonstructural determinants of airway calibre, and are most prominent in the central airways due to the regional distribution of muscarinic receptors [109]. There are no data on the effects of anticholinergics on the surfactant system. In contrast, cholinergic agonists can stimulate surfactant secretion [110], but this effect seems to be indirect as it can be blocked by $\beta$-adrenergic antagonists, indicating inhibition of increased adrenergic activity, e.g. in ganglia [111]. In addition, cholinergic agonists stimulate surfactant secretion in vivo and in the isolated perfused lung but lack secretagogue effect on type II cells in vitro [99]. A possible interaction of anticholinergics and the surfactant system has to be elucidated, but seems to be of minor importance in obstructive airways disease.

Theophylline. Theophylline/aminophylline are widely used in COPD and asthma. Pharmacologically, they increase endogenous cyclic adenosine monophosphate (cAMP) by inhibition of the cAMP decomposing enzyme, phosphodiesterase. Cyclic AMP is the intracellular messenger in smooth muscle cells inducing bronchodilation. In addition to bronchodilation, theophylline was recently shown to have immunomodulatory effects $[112,113]$. Aminophylline was demonstrated to release pulmonary surfactant in foetal rabbits [114]. Another study suggested that aminophylline injected into foetal rabbits leads to increased total phospholipid yield from lung lavage fluids and decreased surface tension as measured by static pressure-volume curves [115]. Thus, it seems possible that surfactant and theophylline evoke synergistic effects in relieving and controlling airway obstruction in asthma and COPD.

Ambroxol. Ambroxol has been shown to stimulate surfactant secretion [116, 117]. However, LUSUARDI et al. [92] report only an insignificant increase of BAL phospholipids in COPD patients treated with $150 \mathrm{mg}$ ambroxol-day ${ }^{-1}$ for 2 weeks. Ambroxol, given at high dosage $(1,000 \mathrm{mg}$ daily) in pregnancy, significantly reduced the incidence of IRDS compared to an untreated control group [118]. At present, however, there are neither sufficient nor reliable data to support the alleged clinical effects of ambroxol.

Taken together, antiobstructive therapy, especially corticosteroids, might influence and improve airway surfactant balance. However, it remains to be determined whether pharmacological stimuli can augment surfactant secretion to an extent that could be clinically relevant. The exact mechanisms and the overall effect of pharmacotherapy on surfactant function in obstructive airways disease has to be elucidated by further investigations. 


\section{Future perspectives}

Different aspects of a possible involvement of surfactant in the development of airway obstruction have evolved both theoretically and experimentally. Now, it is essential to investigate changes in composition and function of pulmonary surfactant in obstructive airways disease in more detail to determine the extent of surfactant dysfunction in these diseases. Moreover, the influence of exogenous surfactants on the inflammatory reactions in asthma has to be explored in vitro and in vivo, before we can conduct clinical studies to investigate a possible benefit of exogenous surfactants in asthma and other obstructive airways diseases. Whenever using exogenous surfactant in the treatment of respiratory disorders, one has to consider the possibility of decelerating the secretory rate of endogenous surfactant. However, data available so far do not indicate a major decrease in the secretory rate, nor a feedback inhibition of pulmonary surfactant components [119]. Another important clinical issue would be pharmacological stimulation of endogenous surfactant synthesis and secretion. Therefore, more effective drugs have to be found. Although many of the drugs used in antiobstructive therapy are known stimuli of endogenous surfactant synthesis and/or secretion, their impact on airway surfactant balance is unknown at present, but seems to be of minor importance. However, to succeed in safe and effective ways of manipulating type II cell functions may prove helpful in obstructive lung diseases, as well as in other respiratory disorders.

\section{References}

1. von Neergard K. Neue Auffassungen über einen Begriff der Atemmechanik: die Retraktionskraft der Lunge, abhängig von der Oberflächenspannung der Alveolen. Z Ges Exp Med 1929; 66: 373-381.

2. Avery ME, Mead J. Surface properties in relation to atelectasis and hyaline membrane disease. Am J Dis Child 1959; 97: 517-523.

3. Hamm H, Kroegel C, Hohlfeld J. Surfactant: a review of its functions and relevance in adult respiratory disorders. Respir Med 1996; 90: 251-270.

4. Günther A, Siebert C, Schmidt R, et al. Surfactant alterations in severe pneumonia, acute respiratory distress syndrome, and cardiogenic lung edema. Am J Respir Crit Care Med 1996; 153 (1): 176-184.

5. van de Graaf EA, Jansen HM, Lutter R, et al. Surfactant protein A in bronchoalveolar lavage fluid. $J$ Lab Clin Med 1992; 120: 252-263.

6. doCampo JL, Bertranou EG, Casellas A, Bonatto P, Battellini R. Pulmonary surfactant post cardiac surgery with cardiopulmonary bypass. Am Rev Respir Dis 1990; 141 (Suppl): A512.

7. McGowan FX Jr, Ikegami M, del Nido PJ, et al. Cardiopulmonary bypass significantly reduces surfactant activity in children. J Thorac Cardiovasc Surg 1993; 106 (6): 968-977.

8. Bos JAH, Lachmann B. Effects of artificial ventilation on surfactant function. In: Rügheimer E, ed. New Aspects on Respiratory Failure. Berlin, Heidelberg, New York, Springer, 1992; pp. 194-208.

9. Hohlfeld J, Tschorn H, Tiryaki E, et al. Surfactant protein A (SP-A) alterations in bronchoalveolar lavage of lung transplant patients. Appl Cardiopulm Pathophysiol 1995; 5 (Suppl. 3): 59-61.

10. Kurashima K, Ogawa H, Ohka T, Fujimura M, Matsuda T, Kobayashi T. A pilot study of surfactant inhalation in the treatment of asthmatic attack. Aerugi (Jpn J Allergol) 1991; 40 (2): 160-163.

11. Gregory TJ, Gadek JE, Weiland JE, et al. Survanta supplementation in patients with acute respiratory distress syndrome (ARDS). Am J Respir Crit Care Med 1994; 149 (4/2): A567.

12. Walmrath D, Günther A, Ghofrani HA, et al. Bronchoscopic surfactant administration in patients with severe adult respiratory distress syndrome and sepsis. Am J Respir Crit Care Med 1996; 154: 57-62.

13. Hamm H, Fabel H, Bartsch W. The surfactant system of the adult lung: physiology and clinical perspectives. Clin Invest 1992; 70: 637-657.

14. Mason RJ. Surfactant synthesis, secretion, and function in alveoli and small airways. Respiration 1987; 51 (Suppl. 1): 3-9.

15. Auten RL, Watkins RH, Shapiro DL, Horowitz S. Surfactant apoprotein A (SP-A) is synthetized in airway cells. Am J Respir Cell Mol Biol 1990; 3: 491-496.

16. Crouch E, Rust K, Marienchek W, Parghi D, Chang D, Persson A. Developmental expression of pulmonary surfactant protein D (SP-D). Am J Respir Cell Mol Biol 1991; 5: 13-18.

17. Wohlford-Lenane CL, Snyder JM. Localization of surfactant-associated proteins SP-A and SP-B mRNA in rabbit fetal tissue by in situ hybridization. Am J Respir Cell Mol Biol 1992; 7: 335-343.

18. van Golde LMG, Batenburg JJ, Robertson B. The pulmonary surfactant system: biochemical aspects and functional significance. Physiol Rev 1988; 68: 374-455.

19. Dobbs LG. Pulmonary surfactant. Апnи Rev Med 1989; 40: 431-446.

20. Rich EA. Pulmonary surfactant as a physiologic immunosuppressive agent. J Lab Clin Med 1990; 116: 4-5.

21. Haagsman HP, van Golde LMG. Synthesis and assembly of lung surfactant. Annu Rev Physiol 1991; 53: 441464.

22. Pettenazzo A, Jobe A, Humme J, Seidner S, Ikegami M. Clearance of surfactant phosphatidylcholine via the upper airways in rabbits. J Appl Physiol 1988; 65: 21512155.

23. Gil J, Weibel ER. Extracellular lining of bronchioles after perfusion-fixation of rat lungs for electron microscopy. Anat Rec 1971; 169: 185-200.

24. Yoneda K. Mucus blanket of rat bronchus: an ultrastructural study. Am Rev Respir Dis 1976; 114: 837-842.

25. Bernhard W, von der Hardt H. Bronchiolar surfactant: phospholipid classes and phosphatidylcholine molecular species as indicators of its alveolar origin. Appl Cardiopulm Pathophysiol 1995; 5 (Suppl 3): 6-7.

26. Schürch S, Gehr P, Im Hof V, Geiser M, Green F. Surfactant displaces particles toward the epithelium in airways and alveoli. Respir Physiol 1990; 80 (1): 17-32.

27. Schürch S, Goerke J, Clements JA. Direct determination of surface tension in the lung. Proc Natl Acad Sci USA 1976; 73: 4698-4702.

28. Schürch S, Bachofen H, Weibel ER. Alveolar surface tensions in excised rabbit lungs: effect of temperature. Respir Physiol 1985; 62: 31-45.

29. Lee MM, Schürch S, Roth SH, et al. Effects of acid aerosol exposure on the surface properties of airway mucus. Exp Lung Res 1995; 21: 835-851.

30. Barrow RE. Chemical structure of phospholipids in the 
lungs and airways of sheep. Respir Physiol 1990; 79 (1): $1-8$.

31. Girod S, Fuchey C, Galabert C, et al. Identification of phospholipids in secretory granules of human submucosal gland respiratory cells. J Histochem Cytochem 1991; 39: 193-198.

32. Macklem PT, Proctor DF, Hogg JC. The stability of peripheral airways. Respir Physiol 1970; 8: 191-203.

33. Otis DR, Johnson M, Pedley TJ, Kamm RD. Role of pulmonary surfactant in airway closure: a computational study. J Appl Physiol 1993; 75: 1323-1333.

34. Kamm RD, Schroter RC. Is airway closure caused by a liquid film instability? Respir Physiol 1989; 75 (2): 141-156.

35. Gaver DP, Samsel RW, Solway J. Effects of surface tension and viscosity on airway reopening. J Appl Physiol 1990; 69: 74-85.

36. Halpern D, Grotberg JB. Surfactant effects on fluid-elastic instabilities of liquid-lined flexible tubes: a model of airway closure. J Biomech Eng 1993; 115 (3): 271-277.

37. Liu M, Wang L, Li E, Enhorning G. Pulmonary surfactant will secure free airflow through a narrow tube. J Appl Physiol 1991; 71: 742-748.

38. Enhorning G, Holm BA. Disruption of pulmonary surfactant's ability to maintain openness of a narrow tube. J Appl Physiol 1993; 74 (6): 2922-2927.

39. Bredenberg CE, Paskanik AM, Nieman GF. High surface tension pulmonary edema. J Surg Res 1983; 34: 515-523.

40. Morgenroth K, Bolz J. Morphological features of the interaction between mucus and surfactant in the bronchial mucosa. Respiration 1985; 47: 225-231.

41. Gehr P, Geiser M, Im Hof V, Schürch S, Waber U, Baumann M. Surfactant and inhaled particles in the conducting airways: structural, stereological, and biophysical aspects. Microsc Res Tech 1993; 26 (5): 423-436.

42. De Sanctis GT, Tomkiewicz RP, Rubin BK, Schürch S, King M. Exogenous surfactant enhances mucociliary clearance in the anaesthetized dog. Eur Respir J 1994; 7: 1616-1621.

43. Rensch H, von Seefeld G, Gebhardt VF, Renzow D, Sell PJ. Stop and go particle transport in the peripheral airways? Respiration 1983; 44: 346-350.

44. Kakuta Y, Sasaki H, Takishima T. Effect of artificial surfactant on ciliary beat frequency in guinea-pig trachea. Respir Physiol 1991; 83: 313-322.

45. Catanzaro A, Richman P, Batcher S, Hallman M. Immunomodulation by pulmonary surfactant. I Lab Clin Med 1988; 112: 727-734

46. Richman PS, Batcher S, Catanzaro A. Pulmonary surfactant suppresses the immune lung injury response to inhaled antigen in guinea-pigs. J Lab Clin Med 1990; 116 (1): $18-26$.

47. van Iwaarden JF. Surfactant and the pulmonary defense system. In: Robertson B, van Golde LMG, Batenburg JJ, eds. Pulmonary surfactant: From Molecular Biology to Clinical Practice. Amsterdam, London, New York, Tokyo, Elsevier, 1992; 215-227.

48. Tenner AJ, Robinson SL, Borchelt J, Wright JR. Human pulmonary surfactant protein (SP-A), a protein structurally homologous to Clq, can enhance FcR- and CR1-mediated phagocytosis. J Biol Chem 1989; 264: 13923-13928.

49. van Iwaarden F, Welmers B, Verhoef J, Haagsman HP, van Golde LMG. Pulmonary surfactant protein A enhances the host-defense mechanism of rat alveolar macrophages. Am J Respir Cell Mol Biol 1990; 2: 91-98.

50. Benne CA, Kraaijeveld CA, van Strijp JA, et al. Interactions of pulmonary surfactant protein A (SP-A) with influenza A viruses: binding and neutralization. $J$ Infect Dis 1995; 171: 335-341.

51. Malhotra R, Haurum J, Thiel S, Jensenius JC, Sims RB. Pollen grains bind to lung alveolar type II cells (A549) via lung surfactant protein A (SP-A). Biosci Rep 1993; 13: 79-90.

52. Wilsher ML, Parker DJ, Haslam PL. Immunosuppression by pulmonary surfactant: mechanisms of action. Thorax 1990; 45: 3-8.

53. Roth MD, Pinto M, Golub SH, Shau H. Pulmonary surfactant inhibits interleukin-2 induced proliferation and the generation of lymphokine-activated killer cells. Am J Respir Cell Mol Biol 1993; 9: 652-658.

54. Borron P, Veldhuizen RAW, Lewis JF, et al. Surfactant associated protein-A inhibits human lymphocyte proliferation and IL-2 production. Am J Respir Cell Mol Biol 1996; 15: 115-121.

55. Hills BA. Asthma: is there an airway receptor barrier? Thorax 1996; 51: 773-776.

56. Bergmann J, Schnitzler S, Seidel M, Lachmann B. Suppression of angiotensin II-induced contraction of the isolated guinea-pig ileum by alveolar surfactants. Z Erkr Atmorg 1977; 149: 328-330.

57. Hohlfeld J, Molthan J, Hoymann HG, Fabel H, Heinrich U. Aerosolized surfactant inhibits acetylcholine-induced bronchoconstriction in rats in vivo. Am J Respir Crit Care Med 1994; 149 (4/2): A97.

58. Hohlfeld J, Molthan J, Hoymann HG, Fabel H, Heinrich U. Der Effekt von inhaliertem Terbutalin auf die Acetylcholin-induzierte Bronchokonstriktion wird durch vernebeltes Surfactant nicht verstärkt. Pneumologie 1994; 48 (Suppl. 2): 623

59. So KL, Gommers D, Lachmann B. Bronchoalveolar surfactant and intratracheal adrenaline. Lancet 1993; 341: 120-121.

60. Wiggs BR, Bosken C, Paré PD, James A, Hogg JC. A model of airway narrowing in asthma and chronic obstructive pulmonary disease. Am Rev Respir Dis 1992; 145: $1251-1258$.

61. Brusasco V, Pellegrino R, Violante B, Crimi E. Relationship between quasi-static pulmonary hysteresis and maximal airway narrowing in humans. J Appl Physiol 1992; 72: 2075-2080.

62. Yager D, Kamm RD, Drazen JM. Airway wall liquid: sources and role as an amplifier of bronchoconstriction. Chest 1995; 107 (Suppl. 3): 105S-110S.

63. Yager D, Butler JP, Bastacky J, Israel E, Smith G, Drazen J. Amplification of airway constriction due to liquid filling of airway interstices. J Appl Physiol 1989; 66: 28732884.

64. Persson CGA. Airway microcirculation, oedema and exudation. Eur Respir Rev 1995; 5 (29): 195-201.

65. Ikegami M, Jobe A, Jacobs H, Lam R. A protein from airways of premature lambs that inhibits surfactant function. J Appl Physiol: Respirat Environ Exercise Physiol 1984; 57: 1134-1142.

66. Seeger W, Stohr G, Wolf HRD, Neuhof H. Alteration of surfactant function due to protein leakage: special interaction with fibrin monomer. J Appl Physiol 1985; 58: 326-338.

67. Fuchimukai T, Fujiwara T, Takahashi A, Enhorning G. Artificial pulmonary surfactant inhibited by proteins. $J$ Appl Physiol 1987; 62: 429-437.

68. Enhorning B, Duffy LC, Welliver RC. Pulmonary surfactant maintains patency of conducting airways in the rat. Am J Respir Crit Care Med 1995; 151: 554-556. 
69. Postle AD. Lung surfactants and asthma. Clin Exp Allergy 1995; 25: 1030-1033.

70. Liu M, Wang L, Enhorning G. Surfactant dysfunction develops when the immunized guinea-pig is challenged with ovalbumin aerosol. Clin Exp Allergy 1995; 25: 1053-1060.

71. Lemarchand P, Chinet T, Collignon MA, Urzua G, Barritault L, Huchon GJ. Bronchial clearance of DTPA is increased in acute asthma but not in chronic asthma. Am Rev Respir Dis 1992; 145: 147-152.

72. Becher G. Lung surfactant prevents allergic bronchial constriction in ovalbumin sensitized guinea-pigs. Biomed Biochim Acta 1985; 44: K57-K61.

73. Lachmann B, Becher G. Protective effect of lung surfactant on allergic bronchial constriction in guinea-pigs. Am Rev Respir Dis 1986; 133 (Suppl.): A118.

74. Liu M, Wang L, Li E, Enhorning G. Pulmonary surfactant given prophylactically alleviates an asthma attack in guinea-pigs. Clin Exp Allergy 1996; 26: 270-275.

75. Veldhuizen RA, Hearn SA, Lewis JF, Possmayer F. Surface area cycling of different surfactant preparations: SP-A and SP-B are essential for large-aggregate integrity. Biochem J 1994; 300: 519-524.

76. Broide DH, Lotz M, Cuomo AJ, Coburn DA, Federman EC, Wasserman SI. Cytokines in symptomatic asthma airways. J Allergy Clin Immunol 1992; 89: 958-967.

77. Osborn L, Kunkel S, Nabel GJ. Tumor necrosis factoralpha and interleukin-1 stimulate the human immunodeficiency virus enhancer by activation of the nuclear factor-kappa B. Proc Natl Acad Sci USA 1989; 86: 2336-2340.

78. Siebenlist U, Franzoso G, Brown K. Structure, regulation and function of NF-kappa B. Annu Rev Cell Biol 1994; 10: 405-455.

79. Antal JM, Divis LT, Erzurum SC, Wiedemann HP, Thomassen MJ. Surfactant suppresses NF- $\kappa B$ activation in human monocytic cells. Am J Respir Cell Mol Biol 1996; 14: 374-379.

80. Bachofen H, Hildebrandt J, Bachofen M. Pressure-volume curves of air- and liquid-filled excised lungs: surface tension in situ. J Appl Physiol 1970; 29: 422-431.

81. Wilson TA, Bachofen H. A model for mechanical structure of the alveolar duct. J Appl Physiol: Respirat Environ Exercise Physiol 1982; 52: 1064-1070.

82. Hyatt RE, Rodarte JR, Wilson TA, Lambert RK. Mechanisms of expiratory flow limitation. Ann Biomed Eng 1981; 9: 489-499.

83. Wirtz HR, Dobbs LG. Calcium mobilization and exocytosis after one mechanical stretch of lung epithelial cells. Science 1990; 250 (4985): 1266-1269.

84. Froese AB, McCulloch PR, Sugiura M, Vaclavik S, Possmayer F, Moller F. Optimizing alveolar expansion prolongs the effectiveness of exogenous surfactant therapy in the adult rabbit. Am Rev Respir Dis 1993; 148 (3): $569-577$.

85. Wirtz H, Schmidt M. Ventilation and secretion of pulmonary surfactant. Clin Invest 1992; 70: 3-13.

86. Wright JR, Clements JA. Metabolism and turnover of lung surfactant. Am Rev Respir Dis 1987; 135: 426-444.

87. Mason RJ. Surfactant secretion. In: Robertson B, van Golde LMG, Batenburg JJ, eds Pulmonary Surfactant: From Molecular Biology to Clinical Practice. Amsterdam, London, New York, Tokyo, Elsevier, 1992; 295-312.

88. Nicholas TE, Power JH, Barr HA. Surfactant homeostasis in the rat lung during swimming exercise. $J$ Appl Physiol: Respirat Environ Exercise Physiol 1982; 53: 314-324.
89. Finley TN, Ladman AJ. Low yield of pulmonary surfactant in cigarette smokers. $N$ Engl J Med 1972; 286: 223-227.

90. Low RB, Davis GS, Giancola MS. Biochemical analyses of bronchoalveolar lavage fluids of healthy human volunteer smokers and nonsmokers. Am Rev Respir Dis 1978; 118: 863-875.

91. Hughes DA, Haslam PL. Effect of smoking on the lipid composition of the lung lining fluid and relationship between immunostimulatory lipids, inflammatory cells and foamy macrophages in extrinsic allergic alveolitis. Eur Respir J 1990; 3: 1128-1139.

92. Lusuardi M, Capelli A, Carli S, Tacconi MT, Salmona M, Donner CF. Role of surfactant in chronic obstructive pulmonary disease: therapeutic implications. Respiration 1992; 59 (Suppl. 1): 28-32.

93. Schmekel B, Bos JA, Khan AR, Wohlfart B, Lachmann B, Wollmer P. Integrity of the alveolar-capillary barrier and alveolar surfactant system in smokers. Thorax 1992; 47: 603-608.

94. Mancini NM, Bene MC, Gerard H, et al. Early effects of short-time cigarette smoking on the human lung: a study of bronchoalveolar lavage fluids. Lung 1993; 171 (5): 277-291.

95. Higenbottam T. Lung lipids and disease. Respiration 1989; 55 (Suppl. 1): 14-27.

96. Oetomo SB, Dorrepaal C, Bos H, et al. Surfactant nebulization does not alter airflow obstruction and bronchial responsiveness to histamine in asthmatic children. Am J Respir Crit Care Med 1996; 153: 1148-1152.

97. Wirtz H, Habscheid W, Ertl G, Schmidt M, Kochsiek K. Exogenous surfactant application in respiratory failure due to chronic obstructive pulmonary disease. Respiration 1995; 62: 157-159.

98. Svedmyr N. Adrenergic beta agonists and corticosteroids in obstructive lung disease. Eur Respir Rev 1995; 5 (31): 339-346.

99. Brown LAS, Longmore WJ. Adrenergic and cholinergic regulation of lung surfactant secretion in the isolated perfused lung and in the alveolar type II cell in culture. J Biol Chem 1981; 256: 66-72.

100. Dobbs LG, Mason RJ. Pulmonary alveolar type II cells isolated from rats; release of phosphatidylcholine in response to $\beta$-adrenergic stimulation. J Clin Invest 1979; 63: 378-387.

101. Mettler NR, Gray ME, Schuffman S, LeQuire VS. Betaadrenergic induced synthesis and secretion of phosphatidylcholine by isolated alveolar type II cells. Lab Invest 1981; 45: 575-586.

102. Fisher AB, Dodia C, Chander A. Secretagogues for lung surfactant increase lung uptake of alveolar phospholipids. Am J Physiol 1989; 257: L248-L252.

103. Bergman B. Beta-mimetics and the preterm neonatal lung. Acta Physiol Scand 1981; 113 (Suppl.): 1-52.

104. van Golde LMG. Synthesis of surfactant lipids in the adult lung. Annu Rev Physiol 1985; 47: 765-774.

105. Pope TS, Smart DA, Rooney SA. Hormonal effects on fatty-acid synthase in cultured fetal rat lung; induction by dexamethasone and inhibition of activity by triiodothyronine. Biochim Biophys Acta 1988; 959: 169177.

106. Young SL, Silbajoris R. Dexamethasone increases adult rat lung surfactant lipids. J Appl Physiol 1986; 60: $1665-1672$.

107. Young SL, Ho YS, Silbajoris RA. Surfactant apoprotein in adult rat lung compartments is increased by dexamethasone. Am J Physiol 1991; 260: 161-167. 
108. Gross NJ, Skorodin MS. Role of parasympathetic system in airway obstruction due to emphysema. $N$ Engl $J$ Med 1984; 311: 421-425.

109. Barnes PJ. Neural control of human airways in health and disease. Am Rev Respir Dis 1986; 134: 1289-1314.

110. Corbet AJS, Flax P, Rudolph AJ. Reduced surface tension in lungs of fetal rabbits injected with pilocarpine. J Appl Physiol 1976; 41: 7-14.

111. Massaro D, Clerch L, Massaro GD. Surfactant secretion: evidence that cholinergic stimulation of secretion is indirect. Am J Physiol 1982; 243: C39-C49.

112. Jaffar ZH, Sullivan P, Page C, Costello J. Low-dose theophylline modulates T-lymphocyte activation in allergen-challenged asthmatics. Eur Respir J 1996; 9: 456-462.

113. Pedersen B, Dahl R, Karlström R, Peterson CGB, Venge $P$. Eosinophil and neutrophil activity in asthma in a oneyear trial with inhaled budesonide: the impact of smoking. Am J Respir Crit Care Med 1996; 153: 1519-1529.

114. Ekelund L, Burgoyne R, Brymer D, Enhorning G. Pulmonary surfactant release in fetal rabbits as affected by terbutaline and aminophylline. Scand J Clin Lab Invest 1981; 41: 237-245.

115. Corbet AJ, Flax P, Alston C, Rudolph AJ. Effect of aminophylline and dexamethasone on secretion of pulmonary surfactant in fetal rabbits. Pediatr Res 1978; 12 : 797-799.

116. Post M, Batenburg JJ, Schuurmans EAJM, Odenborg V, van der Molen AJ, van Golde LMG. The perfused rat lung as a model for studies on the formation of surfactant and the effect of ambroxol on this process. Lung 1983; 161: 349-359.

117. Zavattini G, Leproux GB, Daniotti S. Ambroxol. In: Braga PC, Allegra L, eds. Drugs in Bronchial Mucology. New York, Raven Press, 1989: pp. 263-291.

118. Bottino S, De Micheli C, Arosio P, Marini MG, Pierfederici P. Profilassi della RDS neonatale in gestanti con ipertensione. Neonatologica 1989; (Suppl.): 20-23.

119. Oetomo SB, Lewis J, Ikegami M, Jobe AH. Surfactant treatments alter endogenous surfactant metabolism in rabbit lungs. J Appl Physiol 1990; 68: 1590-1596. 